\title{
Correction to: Sputtered chromium nitride/carbon nanotubes hybrid structure for electrochemical capacitors
}

\author{
Huazhong Liu ${ }^{1,2} \cdot$ Wenxuan $\mathrm{He}^{1} \cdot$ Xiaolan Wang ${ }^{2} \cdot{\text { Zhigao } \mathrm{Lan}^{2} \cdot \text { Huoxi Xu }}^{2}$
}

Published online: 18 March 2021

(c) The Author(s), under exclusive licence to Springer-Verlag GmbH, DE part of Springer Nature 2021

Correction to: Applied Physics A (2021) 127:108

https://doi.org/10.1007/s00339-020-04264-0

In the original publication of the article, one of the first author's affiliation was not included. The correct affiliations appear as below.

Correct affiliations:

${ }^{1}$ Department of Basic Courses, Wuhan Donghu University, Wuhan, China

${ }^{2}$ School of Physics and Telecommunications, Huanggang Normal University, Huanggang, China

The correct copyright holder name is "The Author(s), under exclusive licence to Springer-Verlag GmbH, DE part of Springer Nature".

Publisher's Note Springer Nature remains neutral with regard to jurisdictional claims in published maps and institutional affiliations.

The original article can be found online at https://doi.org/10.1007/ s00339-020-04264-0.

Huazhong Liu

zhonghualiu02@gmail.com

1 Department of Basic Courses, Wuhan Donghu University, Wuhan, China

2 School of Physics and Telecommunications, Huanggang Normal University, Huanggang, China 